Portland State University

PDXScholar

$11-2006$

\title{
A Transmission Electron Microscope for Lecture Demonstrations
}

\author{
J. A. Panitz \\ University of New Mexico - Main Campus \\ Gertrude Rempfer \\ Portland State University
}

Follow this and additional works at: https://pdxscholar.library.pdx.edu/phy_fac

Part of the Physics Commons

Let us know how access to this document benefits you.

\section{Citation Details}

Panitz, J. A. and Rempfer, Gertrude. (2006). A transmission electron microscope for lecture demonstrations. American Journal of Physics, 74, 953-956.

This Article is brought to you for free and open access. It has been accepted for inclusion in Physics Faculty Publications and Presentations by an authorized administrator of PDXScholar. Please contact us if we can make this document more accessible: pdxscholar@pdx.edu. 


\title{
A transmission electron microscope for lecture demonstrations
}

\author{
J. A. Panitz \\ Department of Physics and Astronomy, University of New Mexico, Albuquerque, New Mexico 87131 \\ Gertrude Rempfer \\ Department of Physics, Portland State University, Portland, Oregon 97207
}

(Received 15 February 2006; accepted 4 August 2006)

\begin{abstract}
A simple transmission electron microscope (TEM) suitable for lecture demonstrations is described. In this TEM electrons are created in a glow discharge between two parallel electrodes in air at a reduced pressure. The electrons are collimated by a small hole in the anode, focused by a solenoid that acts as an electromagnetic lens, and imaged on a thin layer of phosphor deposited inside an Erlenmeyer flask. An image of a biological sample placed between the source and the lens can be magnified about 20 times. The microscope uses inexpensive components that can be quickly assembled during a demonstration. The TEM provides a visual and memorable display that highlights phenomena such as mean-free-path, charged particle optics, electrical discharges, and cathodoluminescence. (C) 2006 American Association of Physics Teachers.
\end{abstract}

[DOI: 10.1119/1.2345656]

\section{INTRODUCTION}

The transmission electron microscope (TEM) has become an ubiquitous and powerful tool in science and technology. Since the pioneering work of Ruska in $1931,{ }^{1}$ continual advances have led to the modern electron microscope with a usable magnification greater than $10^{6}$ and a resolution below $1 \AA{ }^{2}$ In this paper we discuss a simple TEM that can be used to demonstrate the physical principles that underlie the operation of modern electron microscopes. The TEM can be assembled during a demonstration from inexpensive components and used to image a biological sample with a magnification of $20 \times$. The production of electrons in a glow discharge, their mean-free-path in a vacuum, their helical trajectory along magnetic field lines, and their excitation of P1 phosphor (powdered willemite, a mineral commonly used to produce the green color in an oscilloscope display) are dramatically demonstrated. The components of a simple TEM appeared as Fig. 15 in Ref. 3. In this paper we present a description of a complete apparatus and demonstrate its operation (see Fig. 1).

\section{THE ELECTRON SOURCE}

The source of electrons is a glow discharge in air at low pressure. The discharge is contained in a $25 \mathrm{~cm}$ long glass tube with an outside diameter of $32 \mathrm{~mm}$. Rubber stoppers at each end support the anode A at ground potential and the cathode K (see Fig. 2). The cathode is a solid aluminum rod. The anode is an aluminum cap containing an axial hole, $2 \mathrm{~mm}$ in diameter. The cap is bored to fit snugly over the end of one of four rigid copper plumbing tubes $(1 / 2 \mathrm{in}$. inside diameter) soldered to a brass plumbing cross. The hole in the cap establishes a differential pressure between the glass tube and a vacuum pump connected to the cross. A variable leak valve controls the pressure in the cross and therefore in the glass tube. ${ }^{4}$ The hole in the anode cap also serves to collimate the electrons that strike the anode and create the electron beam that is the source of illumination. The same source of illumination was used in the earliest electron microscopes. ${ }^{5}$ Current commercial electron microscopes use thermal or field electron emission from fine wire filaments as their illumination source because of their lower energy spread and higher current density.

A mechanical vacuum pump is attached to the cross. When the pump is turned on, the resistance of the AK gap is infinite, no current flows between the anode and the cathode and the maximum power supply voltage appears across the gap. ${ }^{6}$ As the pressure is reduced a glow discharge ignites, presumably initiated by a cosmic ray event or field electron emission at the cathode surface. ${ }^{7}$ When the glow discharge is established current flows across the AK gap and the discharge undergoes characteristic changes in appearance as a function of pressure (see Fig. 3). Striations appear in the discharge and disappear through the anode opening. When the striations appear, the voltage across the AK gap drops to $550 \mathrm{~V}$, corresponding to a current of $3.19 \mathrm{~mA}$ and a gap resistance of $172 \mathrm{k} \Omega$. When imaging conditions are reached, the discharge is barely visible, and the mean-free-path in the remainder of the microscope becomes long enough for electrons to illuminate a thin layer of phosphor deposited on the inside of a $250 \mathrm{ml}$ Erlenmeyer flask. ${ }^{8}$ After further pumping an unmagnified focused profile image of the sample appears

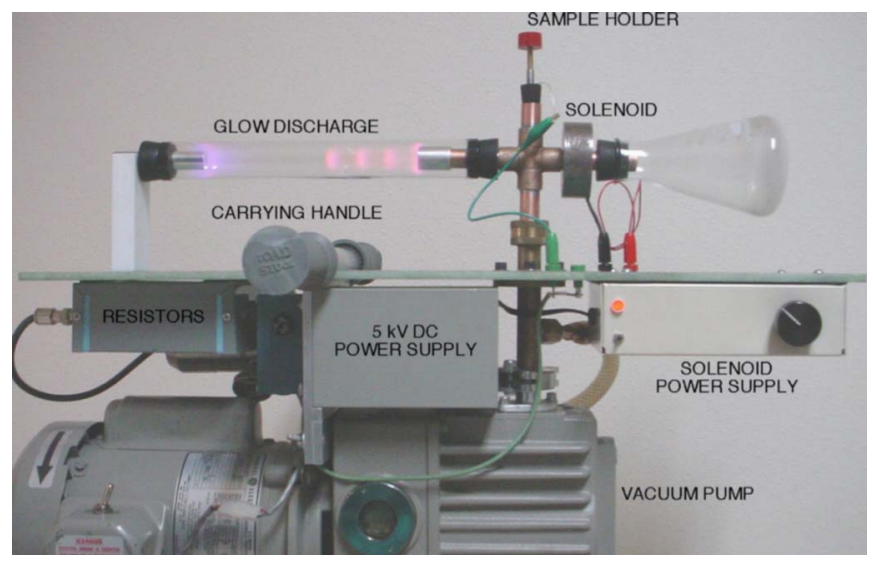

Fig. 1. A simple TEM. 


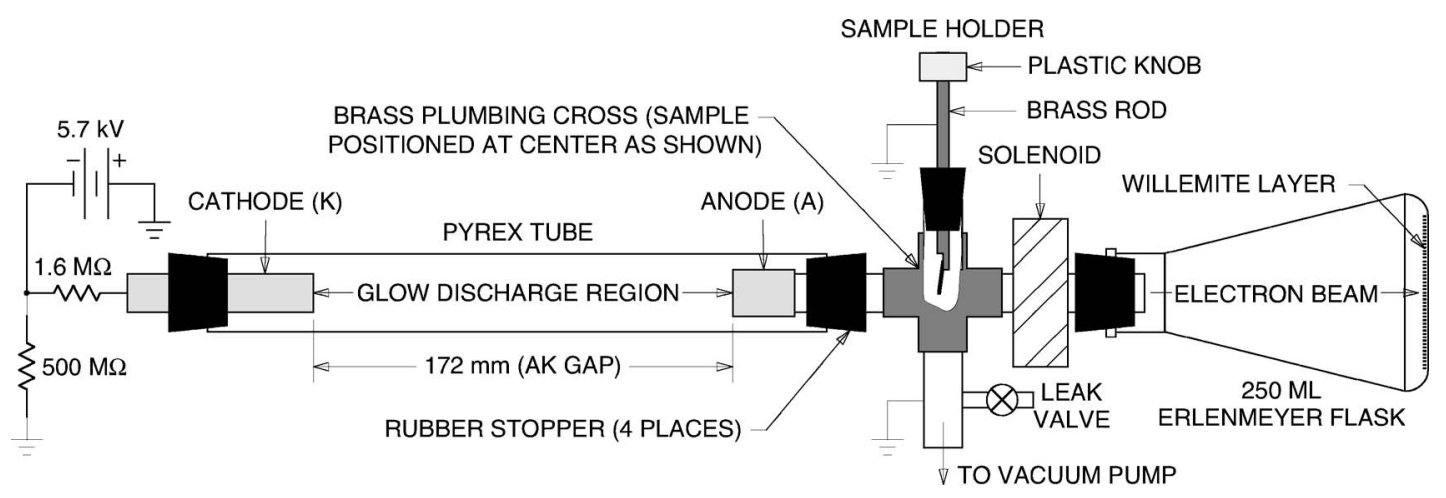

Fig. 2. The components of a simple TEM. The dimensions are to scale but are not critical. The AK gap dimension is shown for reference.

on the phosphor. The leak valve is adjusted to obtain maximum image brightness. If the pressure is too low, the discharge is weak and the brightness decreases. If the pressure is too high, the electron mean-free-path is too small and the brightness decreases. At optimum pressure the voltage across the AK gap increases to about $4.9 \mathrm{kV}$ corresponding to a current of $0.5 \mathrm{~mA}$ and a gap resistance of $9.9 \mathrm{M} \Omega$.

\section{THE SAMPLE}

The sample can be any conducting material. If it is not sufficiently conducting, the image of the sample on the phosphor layer will change with time due to charging and will become distorted. Biological samples are generally nonconducting and must be coated with a thin layer of a conducting material. A good biological sample is a cockroach leg or the leg of a fly attached to a sample holder with colloidal silver and coated with a spray dispersion of graphite in isopropyl

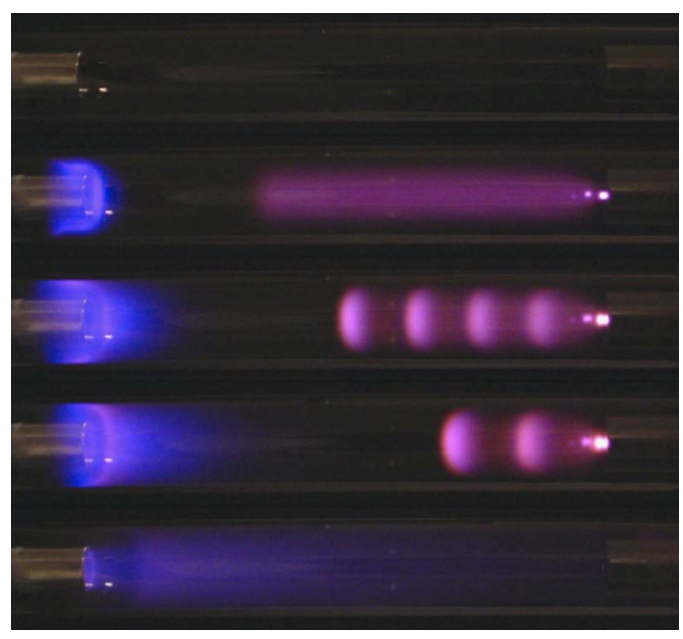

Fig. 3. A glow discharge in air. From top to bottom the pressure is reduced until imaging conditions are satisfied. Electrons emerge as a collimated beam through a hole in the anode (right).

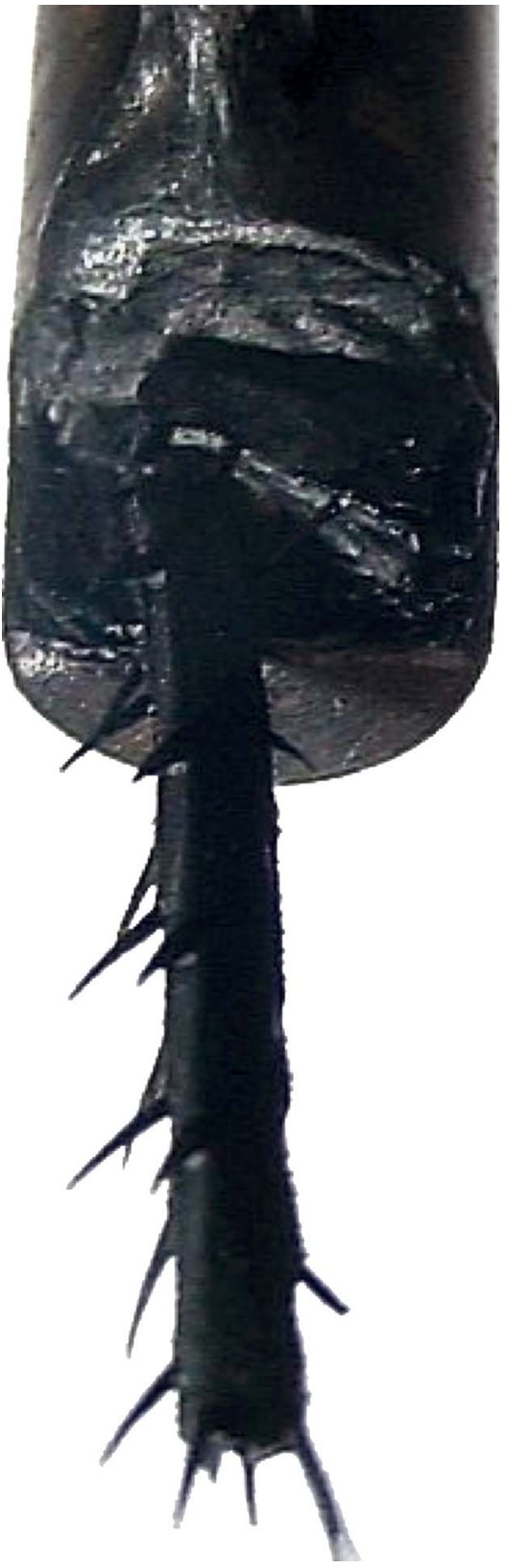

Fig. 4. A biological sample. A cockroach leg was attached to a brass rod $(0.5 \mathrm{~cm}$ in diameter) with a colloidal silver liquid and spray coated with a graphite dispersion in isopropyl alcohol to make it conductive. 


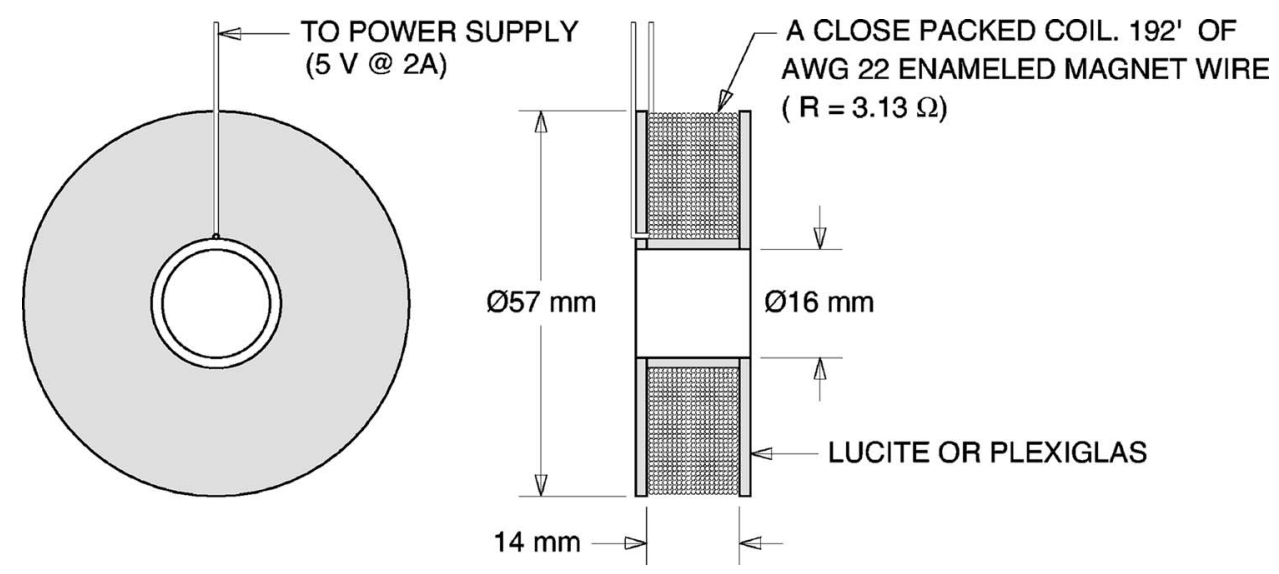

Fig. 5. The electron lens. An air core solenoid, wound on a plastic bobbin is encased in a soft iron or steel housing (not shown) to conduct the magnetic field and concentrate it on the axis. About $3.2 \mathrm{~V}$ at $1 \mathrm{~A}$ produces a field of $8 \mathrm{G}$ on the axis.

alcohol to make it conducting ${ }^{9,10}$ (see Fig. 4). After the colloidal silver is dry, successive coatings of the dispersion should be applied to the sample as needed to eliminate charging. Since the electron kinetic energy is too low to completely penetrate the sample a focused profile image of its contour is produced, similar to the focused profile image of a metal substrate observed in Edge-Projection TEM. ${ }^{11}$ The internal structure of the sample is not imaged.

\section{THE ELECTROMAGNETIC LENS}

An air core solenoid is used as an electromagnetic lens to focus the electron beam onto the phosphor layer. The solenoid is wound on a plastic bobbin and encased in a soft iron or steel housing to conduct the magnetic field and concentrate it on the axis, as shown in Fig. 5. The magnetic flux, which the housing delivers to one end of the solenoid, returns to the other end of the solenoid through the open core, thus completing the magnetic circuit. The magnetic field has a radial component at each end of the solenoid where the magnetic flux bends to go from outside to inside the solenoid or vice-versa. When an electron enters the solenoid, the radial component of the field causes the electron to acquire a

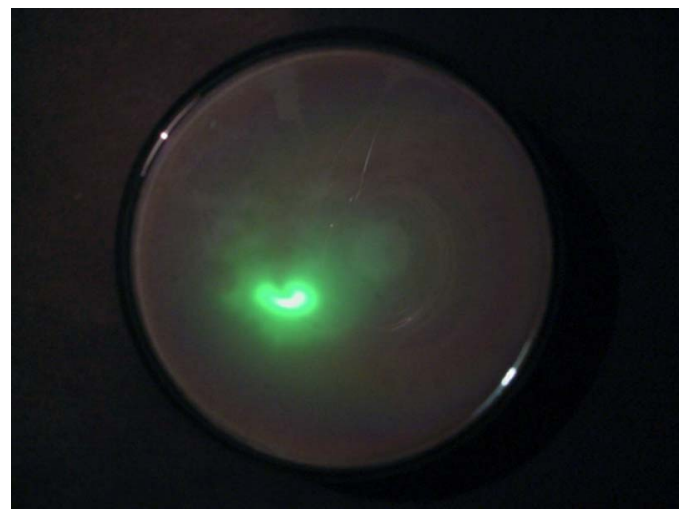

Fig. 6. An unmagnified image. The leak valve is adjusted for maximum image brightness. rotational velocity around the axis (clockwise or counterclockwise depending on the polarity of this end of the solenoid). In either case the interaction of the electron with the axial magnetic field inside the solenoid causes the electron to experience a radial focusing force. As the electron leaves the solenoid, its rotational velocity is removed by the radial magnetic field at the exit, but the electron retains its radial velocity and the angular displacement acquired in the solenoid.

\section{THE IMAGING PROCEDURE}

The imaging procedure is straightforward: (1) Turn on the mechanical vacuum pump and the high voltage power supply. (2) Close the leak valve. (3) Examine the discharge until the striations disappear. (4) When an image appears on the phosphor layer, adjust the leak valve to maximize its brightness as shown in Fig. 6. (5) Adjust the solenoid power supply

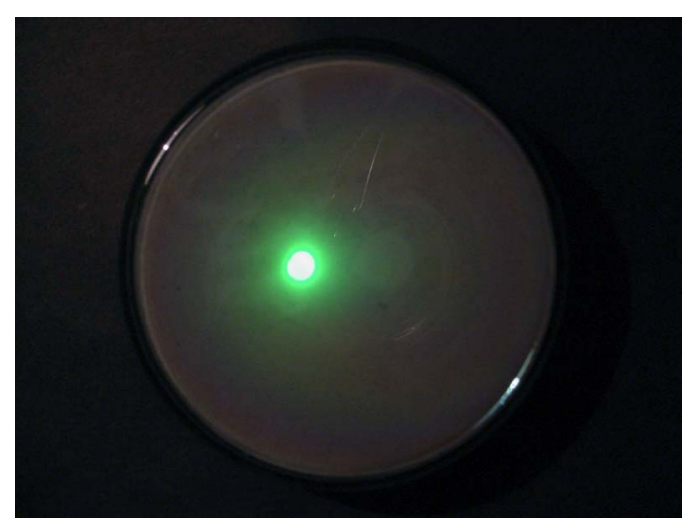

Fig. 7. A focused electron beam. About $0.5 \mathrm{~A}$ is applied to the electron lens. 


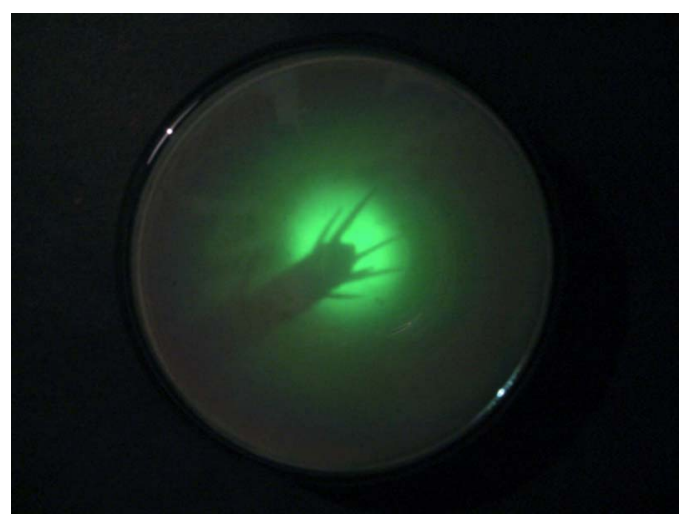

Fig. 8. Cockroach leg magnified about $10 \times(0.8 \mathrm{~A}$ applied to the electron lens).

until focus is achieved as shown in Fig. 7. (6) Adjust the solenoid power supply to magnify the image as shown in Figs. 8 and 9.

\footnotetext{
${ }^{1}$ M. Knolland and E. Ruska, "Beitrag zur geometrischen Elektronenoptik I und II (Contribution to geometrical electron optics)," Ann. Phys. 12, 607-640 (1932); 12, 641-661 (1932).

${ }^{2}$ FEI Company, Titan TEM, 〈www.feicompany.com/〉.

${ }^{3}$ Gertrude F. Rempfer, "Electrostatic electron optics in the 1940s and today," Microscope Soc. Am. Bull. 23, 153-158 (1993).

${ }^{4}$ Varian, variable leak valve, model 951-5106, 〈www.varianinc.com/>.

${ }^{5} \mathrm{E}$. Ruska, "The development of the electron microscope and of electron
}

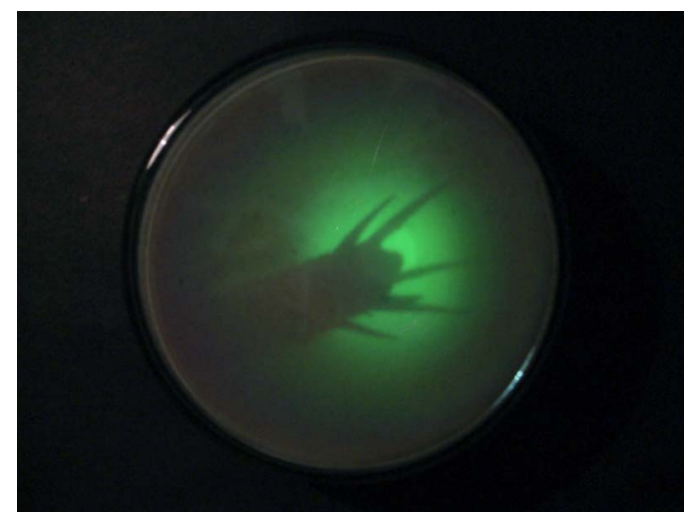

Fig. 9. Cockroach leg magnified about $20 \times(1.0 \mathrm{~A}$ applied to the electron lens).

microscopy. Nobel lecture (physics)," Rev. Mod. Phys. 59, 627-638 (1987).

${ }^{6} \mathrm{~A}$ current limiting resistor (three $5 \mathrm{M} \Omega$ resistors in parallel, $R$ $=1.67 \mathrm{M} \Omega$ ) is wired in series with the power supply and the AK gap. A $150 \mathrm{M} \Omega$ bleeder resistor is wired between the output of the power supply (5 kV@5 mA) and ground.

${ }^{7}$ A. von Engle, Ionized Gases (Oxford University Press, London, 1955).

${ }^{8}$ See, for example, Experimental Innovations in Surface Science, edited by John T. Yates, Jr. (Springer-Verlag, New York, 1998).

${ }^{9}$ Ted Pella, Inc., PELCO colloidal silver liquid, Part No. 16034, $\langle$ www.tedpella.com/〉.

${ }^{10}$ Acheson Colloids Company, Aerodag G, 〈www.achesonindustries.com/〉.

${ }^{11}$ J. A. Panitz and D. G. Bear, "A procedure for increasing the contrast of biological specimens in edge-projection TEM," J. Microsc. 138, 107-110 (1985).

\section{QUANTUM PARADOXES}

"We must learn to cope with the fact that in a quantum system there is a clear and irrevocable distinction between quantum state (while we are not looking-even if the 'looking' is done only in our mind!) and the objective properties revealed by a measurement (information delivered to the macroscopic domain). We must realize that a quantum system is both deterministic and unknowable at the same time! Let it be said once and for all: Quantum paradoxes are paradoxes because of our unavoidable urge to represent mentally what happens inside the quantum domain with familiar images and paradigms from our sensory experience in a classical, macroscopic world. But nothing that transcends physically or informationally from a quantum system into the macroscopic world is intrinsically paradoxical or contrary to the laws of classical and relativistic physics."

J.G. Roederer, Information and Its Role in Nature (Springer, Berlin, Germany, 2005), p. 51. 